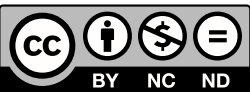

Estudos Teológicos foi licenciado com uma Licença Creative Commons Atribuição - NãoComercial - SemDerivados 3.0 Não Adaptada

http://dx.doi.org/10.22351/etv59i2.3793

\title{
Diaconia e teologia da libertação: APORTES PARA A CONSTRUÇÃO DE UMA METODOLOGIA DIACONAL LIBERTADORA ${ }^{1}$
}

Diakonia and liberation theology: contributions to the construction of a liberating diaconal methodology

\section{Rodolfo Gaede Neto ${ }^{2}$ João Henrique Stumpf ${ }^{3}$ Dionata Rodrigues de Oliveira ${ }^{4}$}

Resumo: O artigo busca explorar a relação histórica e conceitual entre diaconia e teologia da libertação. Estabelece um diálogo objetivando identificar possibilidades da contribuição que a teologia da libertação pode oferecer para a construção de uma metodologia diaconal libertadora, que dialogue com os desafios contextuais colocados pela América Latina à diaconia. A pesquisa demonstra reais possibilidades de contribuição da teologia da libertação a partir de seus dois conceitos medulares. Enquanto o conceito de opção pelos pobres determina o ponto de partida de uma metodologia diaconal libertadora, afirmando os destinatários como sujeitos protagonistas, o conceito de pecado estrutural determina o horizonte dessa metodologia.

Palavras-chave: Diaconia. Teologia da libertação. Metodologia diaconal libertadora.

Abstract: The article seeks to explore the historical and conceptual relationship between diakonia and liberation theology. It establishes a dialogue aiming to identify possible contributions that Liberation Theology can offer to the construction of a liberating diaconal methodology, which dialogues with the contextual challenges posed by Latin America to diakonia. The research demonstrates real possibilities of Liberation Theology contribution from its two spinal concepts. While the concept of option for the poor determines the starting point of a liberating diaconal methodology, affirming the recipients as protagonist subjects, the concept of structural sin determines the horizon of this methodology.

Keywords: Diakonia. Liberation Theology. Liberating diaconal methodology.

1 O artigo foi recebido em 13 de agosto de 2019 e aprovado em 14 de novembro de 2019 com base nas avaliações dos pareceristas ad hoc.

2 Doutor. Faculdades EST, São Leopoldo, RS. E-mail: rodolfo@est.edu.br

3 Mestre. Faculdades EST, São Leopoldo, RS. E-mail: joaohenriques131@gmail.com

4 Bacharel. Faculdades EST, São Leopoldo, RS. E-mail: dionataoliveira@yahoo.com.br 


\section{Introdução}

Em plena Segunda Guerra Mundial, o teólogo e pastor luterano Dietrich Bonhoeffer refere-se ao nazismo a partir da metáfora de um trem genocida que vem em alta velocidade atropelando milhares de pessoas e espalhando vítimas por onde passa. Nesse contexto, Bonhoeffer indagou sobre a postura cristã na situação específica: o papel da igreja é cuidar das vítimas ou tentar parar o trem para que pessoas deixem de ser vitimadas? Sem negar o compromisso cristão com as vítimas, Bonhoeffer aliou-se a um grupo que planejava frear o trem da morte, mesmo que para isso fosse necessário assassinar seu líder maior, Adolf Hitler. As estratégias do grupo foram descobertas pelos nazistas e seus integrantes condenados à pena de morte, incluindo Bonhoeffer. Em 09 de abril de 1945 ele foi enforcado, três semanas antes das tropas aliadas libertarem o campo onde ele estava preso. ${ }^{5}$

Sem entrar no mérito da questão de Bonhoeffer ter participado do complô contra Hitler, assumimos neste artigo a sua indagação original: dentro de um contexto marcado pela atuação de estruturas, sistemas e lógicas que sistematicamente oprimem e vitimam pessoas, qual o papel da igreja? Cuidar das vítimas ou fazer frente aos fatores estruturais que condenam pessoas a uma vida precária ou à própria morte? $\mathrm{O}$ contexto latino-americano, marcado por profundas injustiças que têm sua causa em estruturas políticas e econômicas, representa para muitas pessoas e grupos um verdadeiro trem da morte. Tal tese pode ser comprovada a partir da análise referente a situações de violência (no sentido amplo do termo) sofrida no continente pela população afrodescendente, povos originários, população LGBT + , mulheres, população das periferias das grandes cidades, entre outros grupos e pessoas. Para tais grupos e pessoas a diaconia ${ }^{6}$ cristã deve superar o nível do assistencialismo e o espontaneísmo, sendo capaz de articular sua missão ao conjugar o cuidado imediato às vítimas com a denúncia de estruturas, sistemas e lógicas que condenam tantas pessoas ao sofrimento.

Diante desse horizonte, o presente artigo busca no diálogo com a teologia da libertação subsídios para a elaboração de uma metodologia diaconal libertadora capaz de manter-se atenta às pessoas que sofrem, sem perder de vista as estruturas que lhes causam sofrimento. O caráter de ensaio do presente artigo e o contexto social contemporâneo, marcado pela transitoriedade, impede que ofereçamos uma proposta de metodologia diaconal pronta. $\mathrm{O}$ esforço concentra-se na tentativa de identificar

5 BRANCO, Luis Alexandre Ribeiro. BONHOEFFER: A moralidade e a justificação moral na perspectiva da fé reformada. Verdade na Prática. Disponível em: <https://verdadenapratica.wordpress.com/2017/06/07/ bonhoeffer-a-moralidade-e-a-justificacao-moral-na-perspectiva-da-fe-reformada/> . Acesso em: 12 set. 2019.

6 O presente artigo assume a definição do conceito de diaconia sistematizada por Rodolfo Gaede Neto: "Diaconia é ação salvífica de Deus que motiva, a partir da fé, uma ação da igreja em favor de pessoas que se encontram em situação de sofrimento, pobreza e injustiça, ação esta que se dá através da intervenção consciente, da ação social e política, da ajuda, da atuação pelo amor, da aceitação mútua, inteira, libertadora e curativa, visando transformar uma situação de sofrimento ou injustiça, visando que os pobres resolvam seus problemas e visando um estado de justiça". GAEDE NETO, Rodolfo. A diaconia de Jesus: uma contribuição para a fundamentação teológica da diaconia na América Latina. São Leopoldo: Sinodal; CEBI; São Paulo: Paulus, 2001. p. 40-41. 
elementos, a partir do diálogo com alguns fundamentos e pressupostos da teologia da libertação e com elementos contextuais latino-americanos, que poderão ser usados, em momento posterior, para a sistematização de uma proposta mais completa de metodologia diaconal libertadora. O contexto eclesial em que transitam os pesquisadores é o protestantismo histórico brasileiro.

Para dar conta de tal desafio, o artigo inicia apresentando dados do continente latino-americano e do Brasil, buscando compreender e analisar os desafios contextuais postos à diaconia. $\mathrm{O}$ segundo tópico analisa as possibilidades de diálogo entre a diaconia e a teologia da libertação, a partir de seus dois conceitos medulares, isto é, a opção pelos pobres e a noção de pecado estrutural. O último tópico propõe alguns pressupostos básicos para a elaboração de uma metodologia diaconal libertadora a partir de desafios contemporâneos latino-americanos e do diálogo com dois fundamentos teológicos da teologia da libertação.

\section{Diaconia e contexto latino-americano}

Dados fornecidos pela Comissão Econômica para a América Latina e Caribe (CEPAL) chamam a atenção para o crescimento da pobreza extrema no continente latino-americano: "Em 2017, o número de pessoas vivendo na pobreza chegou a 184 milhões ( $30,2 \%$ da população), dos quais 62 milhões se encontravam na extrema pobreza ( $10,2 \%$ da população, a porcentagem mais alta desde 2008)"”. O relatório do CEPAL afirma ainda que a pobreza extrema atingiu seu nível máximo desde 2008 no continente. "Ainda que a região tenha atingido importantes avanços entre a década passada e meados da presente, desde 2015 foram registrados retrocessos, particularmente em matéria de extrema pobreza"s.

Nesse contexto de aumento da miséria, o Brasil não é exceção, pelo contrário, é o principal responsável pela impulsão da extrema pobreza no continente: "O aumento da pobreza extrema da América Latina se explica, em boa medida, pela má evolução do Brasil, disparadamente o país mais populoso da região que, entre 2015 e 2017, viu a pobreza extrema saltar de $4 \%$ para $5,5 \%$ da sua população" ". Simultaneamente ao aumento da pobreza extrema, observa-se no Brasil, diferentemente do que acontece na maioria dos outros países latino-americanos, um crescimento das desigualdades sociais. ${ }^{10}$ Após um período de 15 anos de diminuição das desigualdades sociais, a mesma volta a crescer na atualidade, segundo dados fornecidos pela OXFAM:

\footnotetext{
CEPAL. A pobreza na América Latina manteve-se estável em 2017, mas a extrema pobreza aumentou, atingindo seu nível mais alto desde 2008, enquanto a desigualdade tem diminuído consideravelmente desde 2000. CEPAL. Disponível em: <https://www.cepal.org/pt-br/comunicados/pobreza-america-latinamanteve-se-estavel-2017-mas-extrema-pobreza-aumentou-atingindo $>$. Acesso em: 15 jul. 2019.

8 CEPAL, 2019.

9 FARIZA, Ignacio; MONTES, Rocío. Impulsionada pelo Brasil, extrema pobreza na América Latina tem pior índice em dez anos. 2019. El País. Disponível em: <https://brasil.elpais.com/brasil/2019/01/15/ internacional/1547563856_964646.html>. Acesso em: 15 jul. 2019.

${ }^{10}$ CEPAL, 2019.
} 
[...] os rendimentos mensais do $1 \%$ mais rico representa 36,3 vezes mais que aqueles dos $50 \%$ mais pobres. Entre 2016 e 2017, os brancos mais ricos tiveram ganhos de rendimentos de $17,35 \%$, enquanto negros incrementaram suas rendas em apenas $8,1 \%$. Pela primeira vez em 23 anos houve recuo na equiparação de renda entre mulheres e homens. O recuo foi verificado entre 2016 e 2017. Pela primeira vez nos últimos 15 anos a relação entre renda média dos $40 \%$ mais pobres e da renda média total foi desfavorável para a base da pirâmide. A metade mais pobre da população teve uma retração de 1,6\% de seus rendimentos entre 2016 e 2017 . Os $10 \%$ mais ricos tiveram crescimento de $2 \%$ em seus rendimentos entre 2016 e $2017^{11}$.

Somadas a essas injustiças de ordem socioeconômica encontram-se muitas outras de ordem cultural e política. Nesse contexto, destaca-se a violência de ordem estrutural sofrida especialmente por mulheres, população afrodescendente, povos originários, migrantes internacionais, população LGBT + , moradores das periferias de grandes cidades, entre outros grupos e pessoas. Todas essas manifestações sociais do pecado humano, desafiam especialmente a dimensão da missão da igreja incumbida de lidar diretamente com tais desafios, a saber, a diaconia.

A diaconia protestante, que é nosso objeto de análise e, ao mesmo tempo, nosso horizonte neste artigo, além de ser interpelada por questões sociais, culturais, econômicas e políticas, é também desafiada a mudar o histórico de sua atuação no mundo, geralmente marcada pelo assistencialismo e espontaneísmo, carecendo de uma atuação mais organizada, transformadora e sistêmica. É o que demonstra um diagnóstico feito na Igreja Evangélica de Confissão Luterana no Brasil (IECLB) em 1998 sobre a atuação diaconal das comunidades de fé dessa igreja: "O diagnóstico identificou que a diaconia ainda era praticamente desconhecida nas comunidades, a prática era pouco reflexiva e marcada pelo assistencialismo e pela espontaneidade"12. Apesar desse diagnóstico representar uma realidade de 20 anos atrás, elementos da realidade da diaconia contemporânea, como o distanciamento de organizações com vínculo confessional das comunidades de fé, a crise do ministério compartilhado, o crescimento de vozes que defendem pautas conservadoras e antidiaconais no interior das comunidades, a oposição a movimentos e organizações que defendem reformas estruturais, entre outras questões, nos levam a suspeitar que a diaconia na IECLB não sofreu grandes mudanças em termos de características nos últimos 20 anos. ${ }^{13}$

Em todo caso, se quiser dialogar com os desafios provenientes do contexto brasileiro, marcado pelo crescimento das injustiças estruturais, a diaconia não só da IECLB, mas também de outras igrejas que compartilham características diaconais semelhantes, precisa construir propostas, paradigmas e metodologias diaconais capazes de conjugar o cuidado imediato de grupos e pessoas que sofrem com atenção

11 OXFAM BRASIL. Um retrato das desigualdades Brasileiras. 2019. Oxfam Brasil. Disponível em: < https:// www.oxfam.org.br/tags/um-retrato-das-desigualdades-brasileiras>. Acesso em: 15 jul. 2019.

12 HERTEL, Hildegart (Coord.). Planejando as ações diaconais da comunidade: e como que se faz isso? Porto Alegre: IECLB, Departamento de Diaconia, 2001. p. 5.

13 Os elementos que configuram a diaconia nessa igreja precisam ser pesquisados com maior profundidade em seus bastidores. 
às estruturas, aos sistemas e às lógicas responsáveis pelo sofrimento dessas pessoas, refletindo e articulando formas de fazer frente às injustiças provenientes de fatores estruturais. Somente assim conseguirá dialogar com a proposta diaconal transformadora e profética testemunhada pelos evangelhos acerca do ministério de Jesus.

Com vistas a propor uma metodologia diaconal atenta a tais questões, suspeitamos que o diálogo com a teologia da libertação será frutífero. Tal suspeita decorre do fato de essa teologia buscar dialogar com desafios contextuais semelhantes aos colocados à diaconia protestante na atualidade.

\section{Diaconia e teologia da libertação}

Antes de aprofundarmos o diálogo entre a diaconia e a teologia da libertação, é importante assinalar que essa teologia, especialmente em suas obras clássicas, não explorou explicitamente o conceito de diaconia. Isso significa que, considerando exceções pontuais, os primeiros teólogos que sistematizaram e desdobraram essa nova forma de fazer teologia no contexto latino-americano praticamente ignoraram esse conceito tão fundamental do ministério de Jesus Cristo e da missão da igreja. Tal constatação é fruto da análise de obras como Teología de la liberación, de Gustavo Gutiérrez (1971); Jesus Cristo Libertador, de Leonardo Boff (1972); Liberación de la teologia, de Juan Luis Segundo (1975) e Raíces de la teología latinoamericana, organizado por Pablo Richard (1985) ${ }^{14}$. A ausência desse conceito pode ser constatada também a partir da análise de outras obras fundamentais da teologia da libertação:

A obra clássica Mysterium Liberationis. Conceptos fundamentales de la teología de la liberación (1990), com dois tomos, organizada por Ignacio Ellacuría e Jon Sobrino, em El Salvador, também não aborda explicitamente o tema da diaconia. Acontece o mesmo com o volumoso: Conceptos fundamentales del cristianismo (1993), com mais de mil e quinhentas páginas, organizada por Casiano Floristán e Juan José Tamayo. Qual a razão ${ }^{15}$

Para Zwetsch, a pouca importância que o conceito diaconia recebeu, especialmente nos escritos clássicos da teologia da libertação, pode ser explicada de duas formas:

[...] a TdL por razões práticas deixou de usar o conceito de diaconia ou por desconhecimento do seu potencial político crítico, ou porque traduziu este conceito com outros

${ }^{14}$ ZWETSCH, Roberto. About Diaconia and Liberation Theology: Theses for debate. 2016. Eurodiaconia. Disponível em: $<$ https://www.eurodiaconia.org/2016/06/brazil-diaconia-and-theology-of-liberation-tesisfor-debate/>. Acesso em: 12 out. 2019.

15 "The classic work Mysterium Liberationis. Conceptos fundamentales de la teología de la liberación (1990), in two volumes, edited by Ignacio Ellacuría and Jon Sobrino, in El Salvador, also does not explicitly address the issue of diaconia. It is the same with the huge Conceptos fundamentales del cristianismo (1993), totalling more than fifteen hundred pages, edited by Casiano Floristán and Juan José Tamayo. For what reason?" (ZWETSCH, 2016) [Tradução nossa]. 
termos mais contemporâneos como: solidariedade, compromisso com os pobres, cidadania, luta pela igualdade e pela democracia de base, e outros ${ }^{16}$.

A pouca importância dada ao conceito diaconia nas obras clássicas da teologia da libertação pode ainda estar ligada ao perfil assistencialista da diaconia, assumida historicamente por muitas igrejas, a qual contribuiu para a construção de uma certa estigmatização do conceito. Ora, se uma das principais preocupações da teologia da libertação, desde o início, foi com a opressão estrutural, logo, abordagens e práticas assistencialistas não lhe interessavam, pois, em sua análise, abordagens com esse caráter cumpriam um papel de anestésico, de "ópio do povo"17, de descarga de consciência por parte de membros que, ao darem "esmola", lavavam as próprias mãos e não buscavam combater as raízes dos problemas sociais. ${ }^{18}$

Em todo caso, a não utilização do conceito diaconia por parte dos clássicos da teologia da libertação não significa que o seu conteúdo não tenha estado presente nas reflexões dessa teologia. Pelo contrário, o núcleo teológico fundamental da teologia da libertação, a pedra angular dessa teologia, a saber, a opção pelos pobres, já atesta que seu aspecto medular é efetivamente diaconal. Dentro desse horizonte, a justificativa dada por Zwetsch de que o conceito de diaconia foi desdobrado em outros termos mais contemporâneos soa como razoável. Termos e conceitos como solidariedade, cidadania, direitos humanos, direitos da natureza, empoderamento, que atualmente ganham grande importância em escritos e demais manifestações da teologia da libertação, ratificam a tese de Zwetsch.

16 " [...] for practical reasons, LT no longer uses the concept of diaconia either through ignorance of its critical political potential, or because it has translated this concept into other more contemporary terms such as solidarity, commitment to the poor, citizenship, the fight for equality and grassroots democracy, and so on" (ZWETSCH, 2016) [Tradução nossa].

17 MARX, Karl; ENGLES, Friedrich. Sur la religion (SR). Paris: Editions Sociales, 1960. p. 42-77. Ver o original Die Deutsche Ideologie. Berlin: Dietz Verlag. p. 22-35. A tradução francesa designa Geistige Produktion por "produção intelectual", mas isso é inexato.

18 Devemos destacar algumas exceções como o livro de Hugo Echegaray: La práctica de Jesús, que foi publicado em 1980, logo após a morte do autor e traduzido em 1984 para o português. Nessa obra o autor dedica um capítulo para trabalhar especialmente o conceito de diaconia, o qual é usado para definir a forma como Jesus entendia que o poder deveria ser usado na sociedade, ou seja, como serviço aos mais necessitados. "Sabe Jesus que um poder não solidário com o povo é poder mentiroso, ameaçado no próprio alicerce" (ECHEGARAY, Hugo. A prática de Jesus. 2. ed. Petrópolis: Vozes, 1984. p. 60). "Em 1993, Casiano Floristán, teólogo espanhol vinculado à Teologia da Libertação, escreveu um livro importante com o título Teologia Practica. Teoría y práctica de la acción pastoral. Ele apresenta as cinco dimensões da ação da igreja: Missio, Didaskalia, Leitourgia, Koinonia e Diakonia. Nesse livro, Floristán dedica nada menos que 69 páginas para a Diaconia ou Serviço da igreja. E ele é o mesmo que organizou com Juan José Tamayo o Dicionário de conceitos fundamentais do cristianismo, publicado no mesmo ano na Espanha e no qual o conceito não está presente. Difícil de entender". "In 1993, Casiano Floristán, a Spanish theologian linked to LT, wrote an important book entitled Teologia Practica. Teoría y práctica de la acción pastoral. It presents the five dimensions of the church's action: Missio, Didaskalia, Leitourgia, Koinonia and Diakonia. In this book, Floristán devotes no fewer than 69 pages to Diaconia or Church Service. And it is he who edited with Juan José Tamayo the Conceptos fundamentales del cristianismo Dictionary (Dictionary of the Fundamental Concepts of Christianity), published the same year in Spain in which the concept is not present. This is difficult to understand". (ZWETSCH, 2016). [Tradução nossa]. 
No próximo tópico serão aprofundados os fundamentos diaconais da teologia da libertação, bem como se buscará identificar os principais aportes que essa teologia pode oferecer diante de desafios contemporâneos postos à diaconia, no intuito de identificar elementos para a elaboração de uma metodologia diaconal libertadora. Na busca por identificarmos possibilidades de contribuição da teologia da libertação clássica para a diaconia protestante na atualidade é essencial identificarmos os fundamentos teológicos principais dessa teologia.

Há um amplo consenso entre teólogos e teólogas da libertação de que o núcleo duro da teologia da libertação é representado pelo conceito de opção pelos pobres ${ }^{19}$. É desse conceito central que se originam todos os desdobramentos e traduções da referida teologia. O teólogo Aquino Júnior destaca a importância desse conceito e sua abrangência:

Podem-se enfatizar mais os aspectos socioeconômicos da pobreza; pode-se tomá-la num sentido mais amplo que abrange também as questões de gênero, etnia, raça, etc. ou tomá-la simplesmente como sinônimo de injustiça e opressão; pode-se estabelecer ou não uma certa hierarquização entre as diversas formas de opressão; pode-se até mesmo discutir se a relação Deus-pobres na teologia deve ser compreendida e formulada nos termos de "relação transcendental" (Sobrino) ou de "princípio primeiro e regente, e princípio segundo e regido" (Boff). De uma forma ou de outra, a "perspectiva do pobre" apresenta-se como algo constitutivo e central dessa teologia. A ponto de que se poderia dizer que, em última instância, a questão decisiva da TdL é sempre a mesma: e os pobres? ${ }^{20}$

19 Nas primeiras obras da teologia da libertação o conceito opção pelos pobres estava fortemente ligado aos pobres socioeconômicos. Logo, outros grupos e pessoas, cerceados de seus direitos e em situação de vulnerabilidade e marginalização, que não necessariamente eram pobres em termos socioeconômicos, não foram levados razoavelmente em consideração. Para José Oscar Beozzo, aos poucos a teologia da libertação foi percebendo que a opressão e a marginalização não estavam restritas aos pobres; iam além das questões socioeconômicas. Foi crescendo a consciência de que uma teologia que almejasse contribuir com a libertação das pessoas em situação de marginalidade e opressão deveria atentar para as especificidades das formas e estruturas de opressão e, também, dos grupos e pessoas (BEOZZO, José Oscar. Como a Teologia da Libertação tem trabalhado o desafio específico da mulher, do índio e do negro? In: TEIXEIRA, Faustino Luiz Couto (Org.). Teologia da libertação: novos desafios. São Paulo: Paulinas, 1991. p. 96). Nas palavras de Leonardo Boff, a teologia da libertação "se deu conta de que pobres-oprimidos possuem muitos rostos e suas opressões são, cada vez, específicas. Não se pode falar de opressão-libertação de forma generalizada. Importa qualificar cada grupo e tomar a sério o tipo de opressão sofrida e sua correspondente libertação ansiada" (BOFF, Leonardo. Quarenta anos da Teologia da Libertação. 2011. Blog Leonardo Boff. Disponível em: <https://leonardoboff.wordpress.com/2011/08/09/ quarenta-anos-da-teologia-da-libertacao/>. Acesso em: 12 set. 2019). Essa tomada de consciência e ampliação do conceito de opressão e de pobre permitiu alargar a abrangência do conceito opção pelos pobres. Esse conceito passou a significar a opção de Deus por todas as pessoas e grupos em situação de vulnerabilidade e marginalidade, aqueles e aquelas que pela violência sofrida por estruturas, sistemas e lógicas, presentes na sociedade, são cerceados em seus direitos humanos. Devem ser incluídos, portanto, nesse conceito grupos e pessoas, como as mulheres vítimas de violência, populações afrodescendentes, povos originários, população LGBT + , migrantes internacionais, pessoas com DST, público idoso, pessoas com deficiência, entre outros. Tendo em vista que o objetivo deste artigo é estabelecer um diálogo entre diaconia e teologia da libertação, especialmente em sua fase clássica, usaremos o conceito opção pelos pobres cientes das limitações que essa expressão tem no horizonte da linguagem inclusiva.

20 AQUINO JÚNIOR, 2010, p. 95-96. 
O teólogo Victor Codina identifica aqui o nascimento dessa teologia: "Eu creio que a Teologia da Libertação nasce de uma experiência espiritual que brota do contato com a realidade, com os pobres, com a miséria do continente. Há como um sacudir-se por dentro, um compreender que isto Deus não quer [...]"21. Em última análise, o conceito de opção pelos pobres na teologia da libertação deriva-se da percepção da opção do próprio Deus revelado em Jesus Cristo: "Jesus reúne em torno de si mesmo o povo dos marginalizados, dos rejeitados, dos oprimidos" ${ }^{22}$. Para José Comblin, essa opção de Deus representa seu anseio profundo pelo resgate de todas as pessoas que se encontram pisoteadas e anuladas em sua dignidade de filhos e filhas de Deus. É como se Deus descesse aos porões da humanidade para devolver a dignidade àqueles e àquelas que foram roubados, para redimir os pisoteados, uma vez que sua vontade é de vida plena e abundante para todas as pessoas (João 10.10). "Não, não foi por simpatia pelo mal e pelo sofrimento, pela miséria dos doentes, paralíticos, cegos e pecadores e toda sorte de marginalizados, desempregados que ele se encontrava no meio deles, mas para ser a promessa e fonte de vida." ${ }^{23}$ Eis aqui a medula da teologia da libertação e, ao mesmo tempo, a constatação de que ela é uma teologia fundamentalmente diaconal. O reconhecimento da presença de Deus entre os grupos e pessoas em estado de exclusão e a explicitação da vontade de Deus em relação à vida plena para todas as pessoas e para toda a natureza representa um chamado para a ação diaconal profética transformadora. Temos aqui a identificação do núcleo duro da teologia da libertação, a saber, a sua decidida atenção à população em estado de vulnerabilidade social no continente.

O segundo pilar dessa teologia, que está intimamente relacionado com o primeiro, é a noção de pecado estrutural. Tal noção surge da percepção de que existem estruturas, sistemas e lógicas, tanto políticas, econômicas, sociais e culturais, que geram pessoas e populações "pobres", que causam e mantêm a miséria existente no planeta e que condenam pessoas e o meio ambiente à morte em seu mais amplo sentido. Por tudo isso "[...] é necessário conhecer o que ocasiona a pobreza no nível social, econômico e cultural’"24. Nesse sentido, há uma abertura para a compreensão de pecado para além do âmbito individual. Esse conceito sustenta que o pecado se petrifica também em estruturas, sistemas e lógicas responsáveis pela dor e sofrimento no mundo:

Paralelamente [...] surgiu a de "pecado estrutural" revelando que há estruturas sociais, econômicas, políticas ou culturais que são pecaminosas - produzem sofrimentos, opressões, o mal - pelo próprio funcionamento da sua lógica, quase que independente das intenções das pessoas envolvidas nestas estruturas ${ }^{25}$.

${ }^{21}$ CODINA, 1991, p. 58.

${ }^{22}$ COMBLIN, 1989, p. 39.

${ }^{23}$ COMBLIN, 1984, p. 31.

${ }^{24}$ GUTIÉRREZ, 2014, p. 76.

${ }^{25}$ MO SUNG, 2007. 
Pode-se identificar, assim, nesses dois conceitos a medula teológica da teologia da libertação. Sem a noção da opção pelos pobres, a teologia da libertação perderia a dimensão da espiritualidade e da compaixão, que enxerga no sofrimento humano e da natureza o sofrimento do próprio Deus, revelado por meio de Jesus Cristo, que se coloca junto às pessoas em situação de exclusão, para redimi-las. Da mesma forma, sem a noção de pecado estrutural a teologia da libertação fica cega em relação às estruturas, aos sistemas e às lógicas de exclusão presentes na sociedade. Sem tal conceito, a teologia latino-americana abriria mão de sua dimensão libertadora.

A partir desses dois conceitos pode-se compreender todo o desenvolvimento da teologia da libertação ao longo de seus quase 50 anos. Sua abertura em relação aos vários tipos de pobres, superando seu reducionismo socioeconômico inicial, foi fundamental para preservar a atualidade e relevância contemporânea do conceito de pobre, conforme sustenta Gustavo Gutiérrez: "A complexidade do universo do pobre e a perspectiva do outro percebidas inicialmente [...], encontram-se hoje mais bem esboçadas com todas as suas dificuldades e sua conflitividade, mas também com todas as suas promessas" ${ }^{26}$. Por outro lado, a percepção da complexidade dos vários tipos de opressão, de suas especificidades ${ }^{27}$, foi fundamental para que a noção de pecado estrutural preservasse a relevância para os dias atuais.

Esses dois fundamentos da teologia da libertação dialogam com desafios postos à diaconia pelo contexto latino-americano. $\mathrm{O}$ conceito de opção pelos pobres e seus desdobramentos não permite que a diaconia esqueça o seu fundamento inegociável, a saber, sua atenção às pessoas que sofrem. Por outro lado, o conceito de pecado estrutural e seus desdobramentos oferece à diaconia a possibilidade de identificar e articular formas de fazer frente às estruturas, sistemas e lógicas que empurram pessoas e a própria natureza para a situação de vulnerabilidade na atualidade. Dentro desse horizonte, o próximo tópico buscará identificar alguns elementos que podem fazer parte de uma metodologia diaconal libertadora a partir do diálogo com os dois conceitos fundamentais da teologia da libertação.

${ }^{26}$ GUTIÉRREZ, Gustavo. Situação e tarefas da Teologia da Libertação. In: GUTIÉRREZ, Gustavo; MÜLLER, Gerhard Ludwig. Ao lado dos pobres: Teologia da Libertação. São Paulo: Paulinas: 2014. p. 76.

${ }^{27}$ BOFF, 2011. 


\section{Contribuições teórico-metodológicas do conceito de opção pelos pobres $^{28}$ e pecado estrutural para a elaboração de uma metodologia diaconal libertadora}

O exercício assumido nesse tópico consiste em identificar algumas das contribuições que os dois conceitos acima citados representam para a elaboração de uma metodologia diaconal libertadora no horizonte de desafios contextuais latino-americanos, a começar pela opção pelos pobres.

A primeira e, possivelmente, mais importante contribuição desse conceito para a diaconia é de caráter espiritual, reconhecendo que a identidade diaconal é o que move cristãos e cristãs para o desenvolvimento da ação. Reconhecer essa identidade é saber que Cristo "veio, não para ser servido, mas para servir e dar a sua vida em resgate por muitos" (Marcos 10.45) ${ }^{29}$ e de que nós somos seguidores e seguidoras desse exemplo; e por isso praticamos diaconia e vemos naqueles e naquelas que sofrem a presença do Cristo crucificado.

O reconhecimento da presença do próprio Cristo junto às pessoas em situação de vulnerabilidade e que clamam por libertação lembra que diaconia e espiritualidade

${ }^{28}$ Dada à limitação do espaço, não foi possível desdobrar neste artigo as implicações estruturais do pecado no que tange à questão ecológica, ao câmbio climático, à crise ambiental que está no centro dos debates da sociedade global nos dias de hoje. Cada vez mais a natureza é incorporada na categoria de pobre, por teólogos e teólogas da libertação, tendo em vista a destruição que ela vem sofrendo nas últimas décadas. "Defendemos, pois, com muitos ecologistas, que a luta cristã de hoje pela libertação dos pobres tem que abranger não unicamente o pobre-pessoa, e sim, também o pobre conquanto criatura num sentido bem mais amplo". WEGNER, Uwe. Bíblia e ecologia. Belo Horizonte: CEBI, 1992. p. 62. Para aprofundar: BOFF, Leonardo. Dignitas Terrae. Ecologia: grito da Terra, grito dos pobres. 2. ed. São Paulo: Ática, 1996; PAPA FRANSCISCO. LAUDATO SI. 2015. Vaticano. Disponível em $<$ http://w2.vatican.va/content/francesco/pt/ encyclicals/documents/papa-francesco_20150524_enciclica-laudato-si.html>. Acesso em: 12 nov. 2019.

29 Jesus entende o seu envio a este mundo como serviço (diaconia): "Eu não vim para ser servido, mas para servir" (Mc 10.45). Em suas atitudes e atividades, como vimos acima [o autor menciona anteriormente em seu livro ações concretas de Jesus para a comunidade, p. ex Mc 10.45ss], ele demonstrou sua diaconia em relação aos últimos. [...] Ao mesmo tempo, porém, sua morte é um servir que transcende a presente realidade e o tempo presente (GAEDE NETO, Rodolfo. A Diaconia de Jesus: contribuição para a fundamentação teológica da Diaconia na América Latina. São Leopoldo: Sinodal, CEBI, São Paulo: Paulus, 2001. p. 80). Não pode haver dúvida de que, segundo o testemunho dos evangelhos, a mensagem de Jesus relativa ao reino de Deus está correlacionada à pessoa, à atuação e à vida de Jesus. De acordo com o testemunho deles (na terminologia do Antigo Testamento), Javé se torna rei por intermédio de um rei (cf. a voz por ocasião do batismo de Jesus: Mateus 3.17, uma citação do Salmo 2.7). Estão ligadas a isso as indicações cronológicas variáveis. "Aproximou-se o reino" - reza o anúncio fundamental. "Tornou-se próximo a vocês" - reza a palavra que os discípulos devem dizer aos enfermos (Lc 10.9). "Sobreveio-vos o reino - assim o próprio Jesus relaciona suas vitórias sobre os demônios com o reino (Mt 12.28). Essas referências cronológicas variáveis constituem uma expressão de que o futuro se torna presente agora e de que o presente somente pode ser entendido em conexão com o futuro (BRANDT, Wilhelm. O serviço de Jesus. In: NORDSTOKKE, Kjell. A Diaconia em perspectiva biblica e histórica. São Leopoldo: Sinodal, 2003. p. 13). Mais do que em palavras, Jesus demonstrou com sua vida morte e ressurreição o conteúdo da palavra diaconia. Em Jesus, diakoneo adquire seu significado. Sua vida foi serviço e doação voluntária por amor. GEORG, Sissi. Diaconia e culto cristão: o resgate de uma unidade. São Leopoldo: Escola Superior de Teologia, Centro de Recursos Litúrgicos, 2006. p. 24. 
são inseparáveis. Diaconia que não parte da fé em Cristo não passa de assistência social ou humanismo, mesmo que bem intencionados. O reconhecimento de Cristo entre os migrantes, entre os povos originários, entre as pessoas violentadas devido à orientação sexual e cor da pele, entre as mulheres em situação de violência, entre todas as pessoas e até junto à própria natureza, que também sofre os efeitos do egoísmo e da ganância humana, é um pressuposto básico daquilo que aqui denominamos metodologia diaconal libertadora. Todos os passos dessa metodologia diaconal proveniente do diálogo com a teologia da libertação são decorrentes dessa espécie de encontro místico com Cristo entre os mais pobres dos pobres. Esse Cristo que quer ser encontrado em meio aos grupos e pessoas em situação de vulnerabilidade e opressão, para que possam ser redimidos e libertados. Nesse sentido, a espiritualidade da libertação é o cerne dessa metodologia, de onde provém todo o seu dinamismo, assim como na teologia da libertação.

O conceito de opção pelos pobres carrega consigo algumas implicações metodológicas de caráter fundamental, conforme sustenta Pablo Richard:

A OPP é uma atitude fundamental que está na raiz de todas as opções de classe, gênero, raça, cultura, geração e ecológica. A OPP urge-nos a olhar a sociedade sempre a partir de baixo, a partir dos excluídos. É uma visão contraposta radicalmente à visão dominante, que olha tudo a partir do poder, a partir do dinheiro, a partir dos valores de eficácia e rentabilidade. [...] está em jogo um encontro privilegiado com Jesus, que vive historicamente nos pobres (Mt 25) ${ }^{30}$.

Conforme sustenta Richard, a opção pelos pobres determina o compromisso com a perspectiva dos interesses e das necessidades dos grupos e pessoas excluídas. Toma-se partido pelos mais fracos. A opção pelos pobres denuncia que, em cenários de conflito entre forças desiguais, como se encontra marcada a realidade latino-americana, não é possível manter uma postura de neutralidade, conforme as palavras de Paulo Freire:

Que é mesmo a minha neutralidade senão a maneira cômoda, talvez, mas hipócrita, de esconder minha opção ou meu medo de acusar a injustiça? “Lavar as mãos' em face da opressão é reforçar o poder do opressor, é optar por ele. Como posso ser neutro diante da situação, não importa qual seja ela, em que o corpo das mulheres e dos homens vira puro objeto de espoliação e de descaso ${ }^{31}$.

Em termos práticos, a opção pelos pobres representa para a metodologia diaconal a tarefa de pensar e articular todos os processos diaconais a partir da perspectiva das pessoas mais vulneráveis. Ela passa a ser pensada e articulada a partir de baixo. Por esse motivo, o processo de conscientização e empoderamento torna-se fundamental. As pessoas alcançadas pela diaconia deixam de ser apenas destinatárias ou

${ }^{30}$ RICHARD, 2006, p. 93.
${ }_{31}$ FREIRE, 2011, p. 109. 
receptoras e tornam-se, acima de tudo, protagonistas. Esse é um dos parâmetros norteadores da metodologia diaconal libertadora.

Ao considerarmos as pessoas em estado de vulnerabilidade como protagonistas da metodologia diaconal, torna-se fundamental a promoção do encontro dessas com as comunidades de fé. Ir ao encontro das pessoas que sofrem e, na medida do possível, incorporá-los nas celebrações, sempre respeitando os credos individuais e grupais, é um pressuposto básico de uma metodologia baseada na opção pelos pobres. ${ }^{32}$

A espiritualidade da opção pelos pobres considera a pessoa ou o grupo em situação de vulnerabilidade como meio privilegiado da revelação de Deus. Se Cristo somente pode ser encontrado junto às pessoas que sofrem, o encontro fraterno e solidário com as pessoas em sofrimento torna-se um aspecto medular dessa metodologia. Promover encontros solidários torna-se uma demanda diaconal. Mesmo tendo ciência das dificuldades, é necessário superar os muros eclesiais para encontrar fisicamente quem sofre nas ruas, nas periferias, no campo, nas prisões, nos hospitais, nas fronteiras [...].

Nesse horizonte, encontra-se uma importante contribuição da teologia feminista para a metodologia diaconal: o resgate de experiências individuais e grupais. Resgatar histórias de vida e experiências de pessoas que se encontram em estado de vulnerabilidade é uma importante forma de mobilizar e quebrar estigmas e preconceitos entre membros das comunidades de fé. Recuperar histórias de vida e a respectiva realidade de determinados migrantes internacionais, de presidiários, de moradores de rua, de prostitutas, de mulheres vítimas da violência doméstica, tem um potencial muito maior de mobilizar iniciativas diaconais das comunidades do que simplesmente apresentar números em relação a tais fenômenos. $\mathrm{O}$ conceito da opção pelos pobres contribui para uma metodologia diaconal libertadora na medida em que lembra que as pessoas e grupos aos quais dirigimos as iniciativas diaconais devem estar sempre no centro da roda, pois são eles e elas os meios privilegiados que Deus escolheu para se revelar à sua igreja. Dentro dessa lógica, a metodologia diaconal libertadora é desenvolvida na perspectiva do sempre desafiador horizonte da libertação.

Enquanto o conceito de opção pelos pobres determina o ponto de partida de uma metodologia diaconal libertadora, afirmando os destinatários como sujeitos protagonistas, o conceito de pecado estrutural aponta para o horizonte dessa metodologia. Seu horizonte é sempre a libertação e a transformação. Como discutido nos tópicos anteriores, o conceito de pecado estrutural afirma que o pecado se cristaliza em estruturas, sistemas e lógicas que escravizam o ser humano e a natureza; logo, é tarefa da diaconia identificar tais pecados estruturais e articular ações que visem à sua superação, sem perder de vista a consciência sobre seus próprios limites.

Essa opressão patrocinada pelo pecado estrutural vai além do nível estrutural propriamente dito, pois envolve o ser humano em sua integralidade. Percebendo isso, desde o início a teologia da libertação sustentou que a libertação deveria levar em con-

32 NORDSTOKKE, Kjell; FEDERAÇÃO LUTERANA MUNDIAL. Diaconia em contexto: transformação, reconciliação, empoderamento: uma contribuição da FLM para a compreensão e a prática da diaconia. Genebra: Federação Luterana Mundial, 2009. p. 21. 
ta a dimensão integral humana. ${ }^{33}$ Nessa direção vai a ponderação de Segundo Galilea, que enfatiza a importância da conscientização:

A libertação cristã propõe, por conseguinte, que a mudança deve processar-se nas duas fontes: na transformação das consciências e na transformação das estruturas. Dialeticamente, uma ajuda a outra, pois o homem influi nas estruturas e estas nele, a um só tempo. Sem esperar fazer uma revolução social para mudar o homem (este continuará igual), nem terminar primeiro a tarefa da educação das consciências para fazer as mudanças estruturais, pois aquelas são educadas também por estas ${ }^{34}$.

A ponderação de Segundo Galilea é importante para a metodologia diaconal na medida em que afirma o seu horizonte, mas acima de tudo, mostra-se fundamental quando demonstra que essa libertação só poderá ser alcançada mediante um processo educativo permanente, que permite à pessoa acompanhada tomar consciência das amarras que a sufocam. Conforme sustenta Paulo Freire:

Pretender a libertação deles sem a sua reflexão no ato desta libertação é transformá-los em objeto que se devesse salvar de um incêndio. É fazê-los cair no engodo populista e transformá-los em massa de manobra. Os oprimidos, nos vários momentos da sua libertação, precisam reconhecer-se como homens, na sua vocação ontológica histórica de ser mais. A reflexão e a ação se impõem, quando não se pretende, erroneamente, dicotomizar o conteúdo da forma histórica de ser do homem ${ }^{35}$.

Por fim, uma última contribuição de um desdobramento do conceito de pecado estrutural para a metodologia diaconal libertadora é a insistência na participação política como forma de buscar a libertação. Nessa direção também assinala Ronaldo Sathler-Rosa:

A mensagem das ações profético-pastorais deve estimular os participantes das comunidades de fé ao engajamento cidadão que porfie por mudanças nos sistemas políticos e culturais. Indivíduos saudáveis não sobrevivem dignamente em sociedades doentias ${ }^{36}$.

O estímulo para que as pessoas participem da vida pública, de movimentos sociais, sindicatos e outros espaços democráticos, é um dos aspectos relevantes que transpassam uma metodologia diaconal libertadora.

33 Apesar de enfatizar que a opressão possui várias dimensões, a TdL nem sempre conseguiu levar a sério, de forma suficiente, todas elas. Somente mais recentemente desdobramentos da TdL, como a teologia feminista, teologia Queer, teologia negra, e assim por diante, conseguiram aprofundar alguns temas negligenciados pela TdL historicamente.

34 GALILEA, 1978, p. 33.

35 FREIRE, Paulo. Pedagogia do oprimido. 44. ed. Rio de Janeiro: Paz e Terra, 2005. p. 59.

36 SATHLER-ROSA, Ronaldo. Cuidado pastoral em perspectiva histórica e existencial: uma revisão crítica. São Paulo: ASTE, 2013. p. 142. 


\section{Conclusão}

$\mathrm{O}$ artigo iniciou trazendo dados que apontam para o aumento da pobreza extrema na América Latina nos últimos anos, concomitantemente ao aumento das desigualdades sociais no Brasil. Tais dados serviram para explicitar o fato de que existem estruturas, sistemas e lógicas atuantes na América Latina que, ao vitimarem pessoas e grupos, desafiam a diaconia cristã a uma tomada de posição. Apesar da teologia da libertação não ter explorado historicamente o conceito de diaconia, o diálogo entre as duas mostra-se bastante frutífero no horizonte dos desafios diaconais contemporâneos.

O conceito da opção pelos pobres ${ }^{37}$ contribui para a elaboração de uma metodologia diaconal libertadora que esteja atenta à dimensão da espiritualidade, da compaixão e do cuidado com os grupos e pessoas em estado de vulnerabilidade. Por outro lado, o conceito de pecado estrutural evidencia e articula a dimensão de libertação da metodologia diaconal, fundamental para que os grupos e as pessoas com as quais a igreja desenvolve suas iniciativas diaconais alcancem a superação de suas amarras, cujas causas estão nas estruturas políticas, econômicas e sociais.

A reflexão proposta neste artigo demostra a possiblidade de contribuição da teologia da libertação para a elaboração de uma metodologia diaconal libertadora no contexto dos desafios latino-americanos contemporâneos. Ciente da delimitação de espaço, assumindo o caráter de ensaio, a pesquisa aqui desenvolvida buscou apenas explicitar e demostrar a fecundidade do diálogo entre diaconia e teologia da libertação, dados os desafios colocados especialmente às igrejas do protestantismo histórico. Cremos que a teologia da libertação é uma importante aliada da diaconia quando busca desenvolver uma visão sistêmica, capaz de conciliar simultaneamente o cuidado com as pessoas e grupos em situação de sofrimento com a atenção e estratégias de superação de estruturas, sistemas e lógicas que vitimam pessoas e a natureza em nosso continente.

${ }^{37}$ Será tarefa para um estudo posterior problematizar o conceito da opção pelos pobres, discutindo os limites da expressão na compreensão da diaconia cristã. "Em coerência com o projeto de reconciliação de Deus, torna-se teologicamente limitada a expressão 'opção pelo pobre'[...]. O problema reside em que essa expressão traz em si a carga de uma linguagem excludente, que é imprópria para se referir ao modo de ser de Deus. [...] Com base nas comunhões de mesa de Jesus, só podemos falar de Deus em linguagem inclusiva" (GAEDE NETO, Rodolfo. Diaconia no contexto afro-brasileiro: um estudo baseado nas comunhões de mesa de Jesus. São Leopoldo: Sinodal; EST, 2014. p. 231). Além das questões de linguagem inclusiva, a expressão opção pelos pobres é limitada por não evidenciar a mensagem central do reino de Deus, de uma sociedade reconciliada, solidária e justa, em que todas as pessoas são incluídas, a não ser quem opta por um projeto contrário, baseado no egoísmo e na ganância (GAEDE NETO, 2014, p. 231-132). A sugestão feita por Peixoto é que o conceito de "opção pelos pobres" seja compreendido no horizonte da "opção pela vida" (PEIXOTO, JORGE apud RAMOS REGIDOR, José. Vinte e Cindo Anos da Teologia da Libertação. In: BOFF, Leonardo (Org.). A Teologia da Libertação: Balanço e Perspectivas. São Paulo: Ática, 1996. p. 59). Em todo caso, estudos posteriores devem discutir e avaliar os limites da expressão opção pelos pobres. 


\section{Referências}

AQUINO JÚNIOR, Francisco de. A teologia como intelecção do reinado de Deus: o método da teologia da libertação segundo Ignacio Ellacuría. São Paulo: Loyola, 2010.

BEOZZO, José Oscar. Como a Teologia da Libertação tem trabalhado o desafio específico da mulher, do índio e do negro? In: TEIXEIRA, Faustino Luiz Couto (Org.). Teologia da libertação: novos desafios. São Paulo: Paulinas, 1991. p. 96-97.

BOFF, Leonardo. Quarenta anos da Teologia da Libertação. 2011. Blog Leonardo Boff. Disponível em: $<$ https://leonardoboff.wordpress.com/2011/08/09/quarenta-anos-da-teologia-da-libertacao/ $>$. Acesso em: 22 abr. 2019.

BRANDT, Wilhelm. O serviço de Jesus. In: NORDSTOKKE, Kjell. A Diaconia em perspectiva bíblica e histórica. São Leopoldo: Sinodal, 2003. p. 9-52.

CEPAL. Disponível em: <https://www.cepal.org/pt-br/comunicados/pobreza-america-latina-manteve-se-estavel-2017-mas-extrema-pobreza-aumentou-atingindo>. Acesso em: 15 jul. 2019. CODINA, Victor. Qual a raiz da Teologia da Libertação? In: TEIXEIRA, Faustino Luiz Couto (Org.). Teologia da libertação: novos desafios. São Paulo: Paulinas, 1991. p. 58-59.

COMBLIN, José. O clamor dos oprimidos: o clamor de Jesus. Petrópolis: Vozes, 1984.

Os pobres como sujeitos da história. In: Revista de Interpretação Bíblica Latino-americana/ RIBLA. Petrópolis, n. 3, p. 36-48, 1989.

ECHEGARAY, Hugo. A prática de Jesus. 2. ed. Petrópolis: Vozes, 1984.

FARIZA, Ignacio; MONTES, Rocío. Impulsionada pelo Brasil, extrema pobreza na América Latina tem pior índice em dez anos. 2019. El País. Disponível em: $<$ https://brasil.elpais.com/ brasil/2019/01/15/internacional/1547563856_964646.html>. Acesso em: 15 jul. 2019.

FREIRE, Paulo. Pedagogia da autonomia: saberes necessários à prática educativa. São Paulo: Paz e Terra, 2011.

. Pedagogia do oprimido. 44. ed. Rio de Janeiro: Paz e Terra, 2005.

GAEDE NETO, Rodolfo. A diaconia de Jesus: uma contribuição para a fundamentação teológica da diaconia na América Latina. São Leopoldo: Sinodal; CEBI; São Paulo: Paulus, 2001.

. Diaconia no contexto afro-brasileiro: um estudo baseado nas comunhões de mesa de Jesus. São Leopoldo: Sinodal; EST, 2014.

GALILEA, Segundo. Teologia da libertação: ensaio de síntese. São Paulo: Paulinas, 1978.

GEORG, Sissi. Diaconia e culto cristão: o resgate de uma unidade. São Leopoldo: Escola Superior de Teologia; Centro de Recursos Litúrgicos, 2006.

GUTIÉRREZ, Gustavo. Situação e tarefas da Teologia da Libertação. In: GUTIÉRREZ, Gustavo; MÜLLER, Gerhard Ludwig. Ao lado dos pobres: Teologia da Libertação. São Paulo: Paulinas: 2014. p. 71-98.

HERTEL, Hildegart (Coord.). Planejando as ações diaconais da comunidade: e como que se faz isso? Porto Alegre: IECLB, Departamento de Diaconia, 2001.

MO SUNG, Jung. Pecado estrutural e as boas intenções. 2007. Adital. Disponível em: $<$ http:// www.adital.com.br/site/noticia2.asp?lang $=P T \&$ cod $=28977>$. Acesso em: 15 abr. 2019.

NORDSTOKKE, Kjell; FEDERAÇÃO LUTERANA MUNDIAL. Diaconia em contexto: transformação, reconciliação, empoderamento: uma contribuição da FLM para a Compreensão e a Prática da Diaconia. Genebra: Federação Luterana Mundial, 2009.

OXFAM BRASIL. Um retrato das desigualdades Brasileiras. 2019. Oxfam Brasil. Disponível em: <https://www.oxfam.org.br/tags/um-retrato-das-desigualdades-brasileiras $>$. Acesso em: 15 jul. 2019.

RAMOS REGIDOR, José. Vinte e Cindo Anos da Teologia da Libertação. In: BOFF, Leonardo (Org.). A Teologia da Libertação: Balanço e Perspectivas. São Paulo: Ática, 1996. p. 17-97. 
RICHARD, Pablo. Força ética e espiritual da teologia da libertação: no contexto atual da globalização. São Paulo: Paulinas, 2006.

SATHLER-ROSA, Ronaldo. Cuidado pastoral em perspectiva histórica e existencial: uma revisão crítica. São Paulo: ASTE, 2013.

ZWETSCH, Roberto. About Diaconia and Liberation Theology: Theses for debate. 2016. Eurodiaconia. Disponível em: $<$ https://www.eurodiaconia.org/2016/06/brazil-diaconia-and-theology-of-liberation-tesis-for-debate/>. Acesso em: 12 out. 2019.

WEGNER, Uwe. Bíblia e ecologia. Belo Horizonte: CEBI, 1992. 